\title{
Comparison of multiple red cell volume methods performed concurrently in premature infants following allogeneic transfusion
}

\author{
Demet Nalbant ${ }^{1}$, Prasad Bhandary', Nell I. Matthews ${ }^{2}$, Robert L. Schmidt ${ }^{1}$, Anna Bogusiewicz ${ }^{2}$, Gretchen A. Cress ${ }^{1}$, \\ M. Bridget Zimmerman ${ }^{3}$, Ronald G. Strauss ${ }^{1,4}$, Donald M. Mock ${ }^{2,5}$ and John A. Widness ${ }^{1}$
}

BACKGROUND: Study of the pathophysiology and treatment of anemia of prematurity is facilitated by direct measurement of red cell volume (RCV) utilizing microliter quantities of blood samples. Our objective was to compare concurrent measurements of multiple direct RCV methods in infants.

METHODS: Eighteen preterm infants receiving clinically indicated transfusions had concurrent flow cytometric determinations of RCV and 24-h red blood cell (RBC) recovery based on donor-recipient differences of biotin-labeled RBCs (BioRBCs), Kidd antigen mismatched RBCs, and fetal hemoglobin-positive $\left(\mathrm{HbF}^{+}\right) \mathrm{RBCs}$. High-performance liquid chromatography (HPLC) was also used for measuring $\mathrm{HbF}$ and adult hemoglobin protein concentrations for the determination of RCV.

RESULTS: Concurrent RCV measurements using BioRBCs (18 and $54 \mu \mathrm{g} / \mathrm{ml}$ ), Kidd antigen, and $\mathrm{HbF}$ flow cytometry were not statistically different compared with RCVs measured using the reference BioRBC density $(6 \mu \mathrm{g} / \mathrm{ml})$. By contrast, the HbF-HPLC method overestimated RCV by $45 \%$ compared with the reference method. All the methods demonstrated 100\% 24-h posttransfusion $\mathrm{RBC}$ recovery $\left(\mathrm{PTR}_{24}\right)$.

CONCLUSION: Because BioRBC, Kidd antigen, and fetal hemoglobin $(\mathrm{HbF})$ flow cytometry are safe and accurate methods requiring $<10 \mu$ of patient blood for determining RCV and PTR $_{24}$ in preterm infants, they can be useful in clinical and research studies of anemia and other conditions.

A nemia is a common and serious clinical problem among critically ill premature infants. Important contributors to anemia of prematurity include low hemoglobin $(\mathrm{Hb})$ at birth, blood loss due to phlebotomy for laboratory testing, and inability of the infant to produce sufficient red blood cells (RBCs) to overcome blood loss and postnatal expansion of blood volume (BV) with rapid growth. Currently, the two most common treatments for anemia in premature infants are allogeneic RBC transfusion and recombinant erythropoietin (1). To assess the effectiveness of these and other therapies, safe, accurate, and versatile methods for determining circulating red cell volume (RCV), BV, and 24-h posttransfusion recovery $\left(\mathrm{PTR}_{24}\right)$ of transfused blood are needed. Among ill premature infants, RCV is deemed a better indicator of the need for RBC transfusion than either whole-blood $\mathrm{Hb}$ or hematocrit (HCT) levels $(2,3)$.

Flow cytometric enumeration of RBCs can be used in the determination of RCV and BV and requires only a few microliters of blood. This method relies on its ability to discriminate transfused from endogenously produced RBC populations. Flow cytometry has been used for detecting fetomaternal hemorrhage $(4,5)$, for determining RBC phenotype following bone marrow transplant (6), for measuring RCV (7-9), for detecting illicit blood transfusions in athletes (10), and for determining RBC survival $(11,12)$. Recently, our group has, for the first time, demonstrated that RCV can be accurately determined in adult humans and sheep using multiple distinct populations of biotin-labeled RBCs (BioRBCs) enumerated by flow cytometry $(8,13)$.

In this study, we extend the previous work with the objective of comparing concurrent RCV determinations using four different methods in very-low-birth-weight (VLBW) premature infants weighing $<1.5 \mathrm{~kg}$ at birth: flow cytometric methods, including (i) multidensity BioRBC, (ii) Kidd antigen (Jka and Jkb) mismatches between adult donor and infant RBCs, and (iii) dilution of infant RBCs containing primarily $\mathrm{HbF}$ by donor RBCs containing primarily adult hemoglobin ( $\mathrm{HbA}$ ); and a non-flow cytometric method that measures change in proportion of $\mathrm{HbA}$ and $\mathrm{HbF}$ proteins using high-performance liquid chromatography (HPLC). Only the biotin labeling method requires labeling of donor RBCs before transfusion. Because of extremely limited recovery data for stored donor blood in infants, we also determined the $\mathrm{PTR}_{24}$ of transfused RBCs using the same methods.

Based on our previous findings in adults $(8,11)$, we hypothesized that (i) RCV determined using RBCs biotinylated at three high biotin densities $(18,54$, and $162 \mu \mathrm{g}$ of biotinylating 
reagent per milliliter RBCs), Kidd antigen mismatch, and $\mathrm{Hb}$ type differences methods would not differ significantly from RCV determined using a previously validated low BioRBC density $(6 \mu \mathrm{g} / \mathrm{ml})$ as the reference method; (ii) allogeneic RBCs would completely equilibrate within the first 20 -min posttransfusion (i.e., there would be no mixing or spleen effect); and (iii) $\mathrm{PTR}_{24}$ assessed by all the methods would not be significantly different than $100 \%$.

\section{RESULTS}

Eighteen premature infants with gestational ages at birth between 26 and 30 wks were studied (Table 1). Mean $( \pm$ SD) birth weight was $0.96 \pm 0.24 \mathrm{~kg}$ (range: $0.39-1.40 \mathrm{~kg}$ ). On the day the study transfusion was administered, infants were $18 \pm 14 \mathrm{~d}$ old (range: $1-45 \mathrm{~d}$ ) with body weights of $1.21 \pm 0.45 \mathrm{~kg}$ (range: $0.37-2.21 \mathrm{~kg}$ ).

\section{Flow Cytometric Identification of RBC Populations}

The four discrete BioRBC densities and the unlabeled RBCs demonstrated complete separation, permitting accurate enumeration of each of the four BioRBC populations (Figure 1a). Pre- and posttransfusion histograms based on Kidd Jka and Jkb antigens also exhibited no overlap of peaks (Figure 1b,c). Because the study transfusion was the first transfusion for this specific infant, there was only a single peak (Jkb. RBCs)

Table 1. Study subject demographics

\begin{tabular}{|c|c|c|c|c|}
\hline $\begin{array}{l}\text { Subject } \\
\text { number }\end{array}$ & $\begin{array}{c}\text { Gestational age } \\
\text { at birth (wk) }\end{array}$ & $\begin{array}{c}\text { Birth } \\
\text { weight (kg) }\end{array}$ & $\begin{array}{l}\text { Study } \\
\text { age (d) }\end{array}$ & $\begin{array}{c}\text { Study } \\
\text { weight }(\mathrm{kg})\end{array}$ \\
\hline $1^{a, b, c}$ & 27.9 & 0.83 & 22 & 1.25 \\
\hline $2^{\mathrm{a}, \mathrm{c}}$ & 28.7 & 1.31 & 40 & 2.21 \\
\hline $3^{\mathrm{a}, \mathrm{c}}$ & 28.0 & 0.88 & 23 & 1.10 \\
\hline $4^{\mathrm{a}, \mathrm{b}, \mathrm{d}}$ & 28.0 & 1.09 & 8 & 0.96 \\
\hline $5^{\mathrm{a}, c, e}$ & 28.7 & 1.37 & 10 & 1.32 \\
\hline $6^{\mathrm{a}, \mathrm{d}, \mathrm{e}}$ & 28.0 & 0.93 & 1 & 0.93 \\
\hline $7^{\mathrm{a}, \mathrm{c}}$ & 29.9 & 0.73 & 3 & 0.76 \\
\hline $8^{a, c, e, f}$ & 30.1 & 1.40 & 33 & 1.96 \\
\hline $9^{a, c e, f}$ & 27.4 & 0.91 & 45 & 1.76 \\
\hline $10^{a, c, f}$ & 26.7 & 0.86 & 33 & 1.55 \\
\hline $11^{\mathrm{a}, \mathrm{c}, \mathrm{f}, \mathrm{g}}$ & 27.4 & 0.83 & 15 & 0.98 \\
\hline $12^{\mathrm{a}, \mathrm{d}, \mathrm{f}}$ & 26.3 & 0.39 & 1 & 0.37 \\
\hline $13^{\mathrm{a}, \mathrm{c}, \mathrm{e}, \mathrm{f}, \mathrm{g}, \mathrm{h}}$ & 27.4 & 1.08 & 15 & 1.20 \\
\hline $14^{\mathrm{a}, \mathrm{c}, \mathrm{e}, \mathrm{f}, \mathrm{g}}$ & 28.9 & 0.92 & 34 & 1.52 \\
\hline $15^{a, b, c, c, f, g}$ & 27.0 & 1.00 & 9 & 0.87 \\
\hline $16^{\mathrm{a}, \mathrm{b}, \mathrm{c}, \mathrm{e}, \mathrm{f}, \mathrm{g}}$ & 27.0 & 0.93 & 13 & 1.06 \\
\hline $17^{a, b, d, e, f, g}$ & 26.3 & 0.95 & 5 & 0.92 \\
\hline $18^{\mathrm{a}, \mathrm{c}, \mathrm{e}, \mathrm{f}, \mathrm{g}}$ & 27.4 & 0.95 & 13 & 0.98 \\
\hline Mean & 27.8 & 0.96 & 18 & 1.21 \\
\hline SD & 1.06 & 0.24 & 14 & 0.45 \\
\hline
\end{tabular}

BioRBC, biotin-labeled RBC; HPLC, high-performance liquid chromatography. ${ }^{a}$ BioRBC, $n=18$. ${ }^{\text {KKidd } J k a ~ m i s m a t c h, ~} n=5$. Peripheral capillary posttransfusion wholeblood sample, $n=14$. 'Central arterial posttransfusion whole-blood sample, $n=4$. ${ }^{\text {eKidd }}$

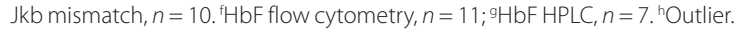

originating from the infant in the pretransfusion sample (Figure 1b). After transfusion of Jkb mismatched RBCs, the expected two peaks were present. By contrast, both pre- and posttransfusion samples from an infant who had already received Kidd antigen mismatched blood before the study showed two distinct peaks (Figure 1c). After the transfusion, the proportion of $\mathrm{Jka}^{-}$donor RBCs increased whereas the proportion of $\mathrm{Jka}^{+}$infant RBCs decreased. The histograms for HbF-positive $\left(\mathrm{HbF}^{+}\right) \mathrm{RBCs}$ in subjects without and with previous transfusions demonstrated peak patterns similar to those for the two Kidd antigens (Figure 1d, e).

\section{Comparison of RCV Measurement Methods by Regression Analysis}

RCV measured at 20-min posttransfusion using the reference BioRBC density agreed well with the RCV measured using the higher BioRBC densities, Kidd antigen, and $\mathrm{HbF}$ flow cytometry methods but not with that measured using the HbF-HPLC method (Figure 2). The agreement of the reference BioRBC method at densities $18,54,162 \mu \mathrm{g} / \mathrm{ml}$ were greater than for the Kidd antigen and $\mathrm{HbF}$ flow cytometry methods as judged by range of the $95 \%$ confidence interval (CI) for both the slope and $y$-intercept (Figure 2a-c; Table 2). Among all the methods, the HbF HPLC method showed the weakest correlation with the reference BioRBC density $\left(R^{2}=0.869\right.$ and the widest 95\% CIs; Figure 2f; Table 2).

There was a single notable outlier RCV determined using the Kidd antigen and both $\mathrm{HbF}$ methods (Subject 13 shown as a triangle in Figure 2d-f). RCV values for this subject were greater than mean $\pm 2 \mathrm{SD}$ relative to the other $\mathrm{RCV}$ values. We have no explanation for this outlier. This point was excluded from the regression analyses.

\section{Comparison of 20- and 90-min Posttransfusion RCV Determinations}

In our previous adult sheep studies, we observed a slowly equilibrating pool of intravascular RBCs that accounted for about one-third of the total circulating RBCs (13). This was likely due to pool of RBCs sequestered in the ovine spleen that equilibrates slowly with the circulating RBCs and BioRBCs. To determine whether a similar phenomenon was present in VLBW infants, we compared paired RCV values at 20- and 90-min posttransfusion using a linear mixed model analysis for repeated measures (Table 3). Differences between mean RCV values at 20 and 90 min were not significant, thus indicating no reservoir of slowly mixing RBCs in the spleen of VLBW infants.

\section{Effect of Individual Method on RCV}

Two statistical comparisons of the RCV results from the individual methods were performed: linear mixed model analysis with repeated measures and Bland-Altman plot analysis. In both comparisons, RCV determined by individual methods was expressed as a ratio relative to the reference BioRBC density RCV. Because mean posttransfusion RCV values at 20 and $90 \mathrm{~min}$ were not significantly different, the linear mixed 


\section{Articles | Nalbant et al.}
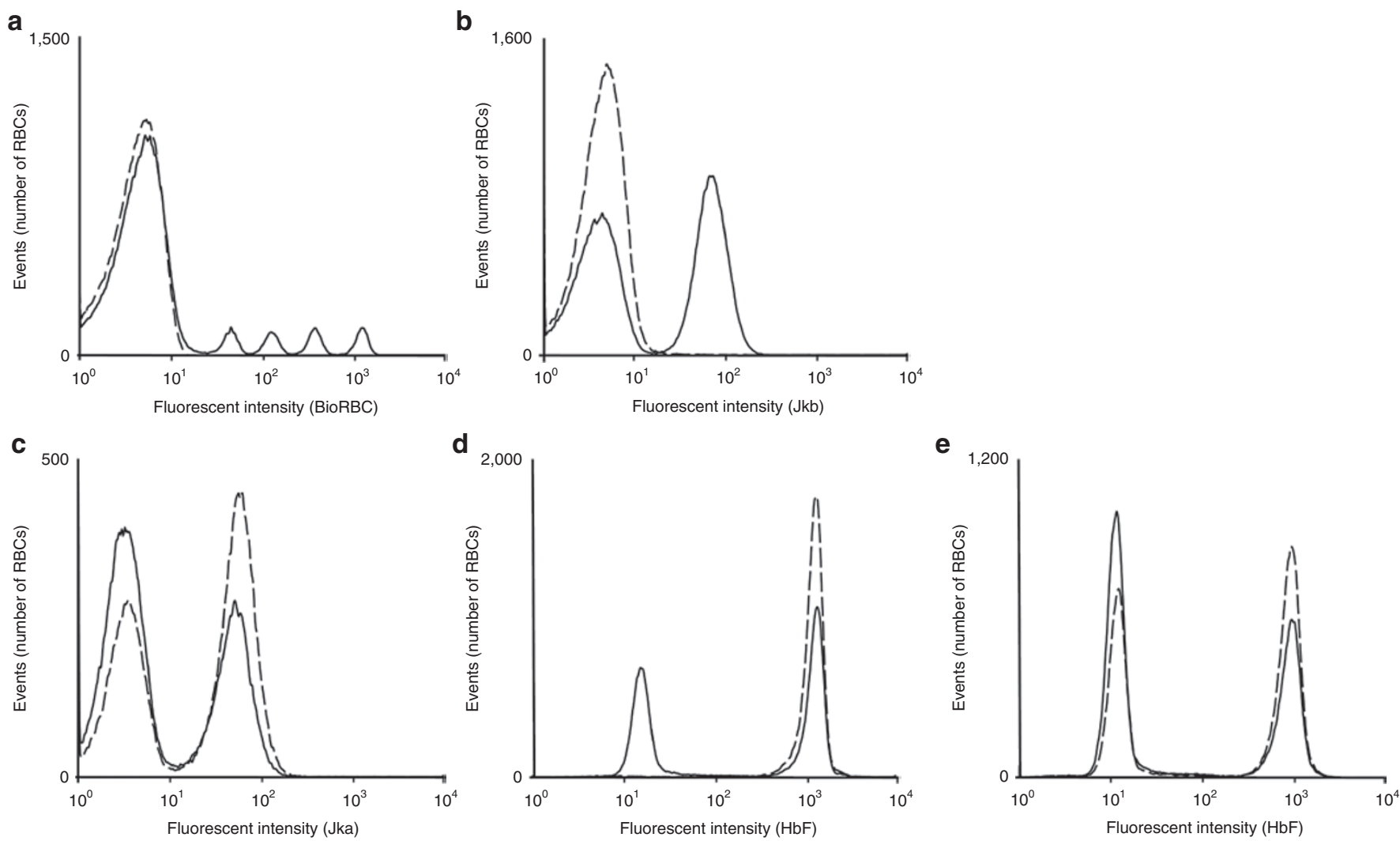

Figure 1. Flow cytometry histograms of pre- and posttransfusion samples showing number of red blood cells (RBCs) enumerated ( $y$-axis) to log of fluorescent intensity ( $x$-axis) showing distinct RBC populations detected by different methods. Dashed lines indicate pretransfusion samples and solid lines indicate posttransfusion sample results. (a) Subject 15, BioRBCs detected using Alexa-streptavidin; (b) Subject 14 with no previous transfusion, Jkb+ RBCs detected using anti-Jkb (infant RBCs are $\mathrm{Jkb}^{-}$and donor RBCs are $\mathrm{Jkb}^{+}$); (c) Subject 4 with a previous transfusion, Jka ${ }^{+}$cells detected using anti-Jka (Infant RBCs are $\mathrm{Jka}^{+}$and donor RBCs are Jka.); (d) Subject 12 with no previous transfusion, $\mathrm{HbF}^{+} \mathrm{RBC}$ s detected using anti-HbF; and (e) Subject 15 with a previous transfusion, $\mathrm{HbF}^{+} \mathrm{RBC}$ s detected using anti-HbF. BioRBC, biotin-labeled RBC; $\mathrm{HbF}$, fetal hemoglobin.

model analysis of the methods was based on the RCV values averaged for these two posttransfusion times. In this analysis, results were deemed not different if the $\pm 95 \%$ CI ratio included 1.0. Mean RCV ratios were not significantly different among the methods with two exceptions: (i) $162 \mu \mathrm{g} / \mathrm{ml}$ BioRBC density overestimated the RCV by $4.4 \%$, a difference likely to be unimportant for most clinical and research applications; and (ii) HbF HPLC overestimated RCV by $44.9 \%$, a large difference (Table 4).

In the second statistical comparison, agreement among the methods for measuring RCV at 20-min posttransfusion was assessed by Bland-Altman plots (Figure 3). Using the reference BioRBC density as the denominator, the ratios of the RCV for each method demonstrated agreement among all methods except for HbF HPLC. For the three higher BioRBC densities, the $95 \%$ limits of agreement with the reference method were as follows: -3.3 to $+6.5 \%$ for $18 \mu \mathrm{g} / \mathrm{ml} ;-4.4$ to $+7.9 \%$ for $54 \mu \mathrm{g} /$ $\mathrm{ml}$; and -7.6 to $+15.6 \%$ for $162 \mu \mathrm{g} / \mathrm{ml}$. Agreement with the reference BioRBC method was not as close for the Kidd antigen (Jkb) or the HbF flow cytometry methods. The limits of agreement were -6.4 to $+19.2 \%$ for Jkb and -9.6 to $+20.1 \%$ for $\mathrm{HbF}$ flow cytometry. The HbF HPLC method significantly overestimated RCV; the limits of agreement were +6.8 to $+56.5 \%$. As with the regression analyses, Subject 13's outlier data point was excluded from the Kidd antigen and both HbF analyses. Due to the small sample number $(n=4)$, comparison of RCV values by the Kidd Jka method against the reference BioRBC density was not performed.

\section{Short-Term Recovery of Transfused RBCs}

To determine $\mathrm{PTR}_{24}$, we assessed the percentage of transfused $\mathrm{RBCs}$ remaining $24 \mathrm{~h}$ after transfusion using the four BioRBC densities, Kidd antigen, and both $\mathrm{HbF}$ methods. Differences in means between $20 \mathrm{~min}$ and $24 \mathrm{~h}$ for each method were tested for significance by mixed model analysis for repeated measures. Mean $\mathrm{PTR}_{24}$ measured by BioRBC for the 14 study subjects were not different between $20 \mathrm{~min}$ and $24 \mathrm{~h}$ (Table 5). Indeed, $\mathrm{PTR}_{24}$ was not significantly different from $100 \%$ for any of the methods (Bonferroni adjusted $P$ values: 0.14 to $>0.99$ ), thus providing evidence that the reticuloendothelial system of VLBW infants does not remove any of the transfused RBCswhether labeled with biotin or differentiated from recipient $\mathrm{RBCs}$ by minor antigen or $\mathrm{HbF}$ - within the first $24 \mathrm{~h}$ posttransfusion. The mean percentage change from $20 \mathrm{~min}$ ranged from a decrease of $-3.7 \%$ (95\% CI: $-9.8 \%, 2.8 \%)$ for $\mathrm{HbF}$ flow cytometry to an increase of $3.7 \%$ (95\% CI: $-2.4 \%, 10.2 \%)$ for Kidd Jkb. Due to the small sample number, data from the Kidd Jka method (two data points) were not analyzed. Because four 

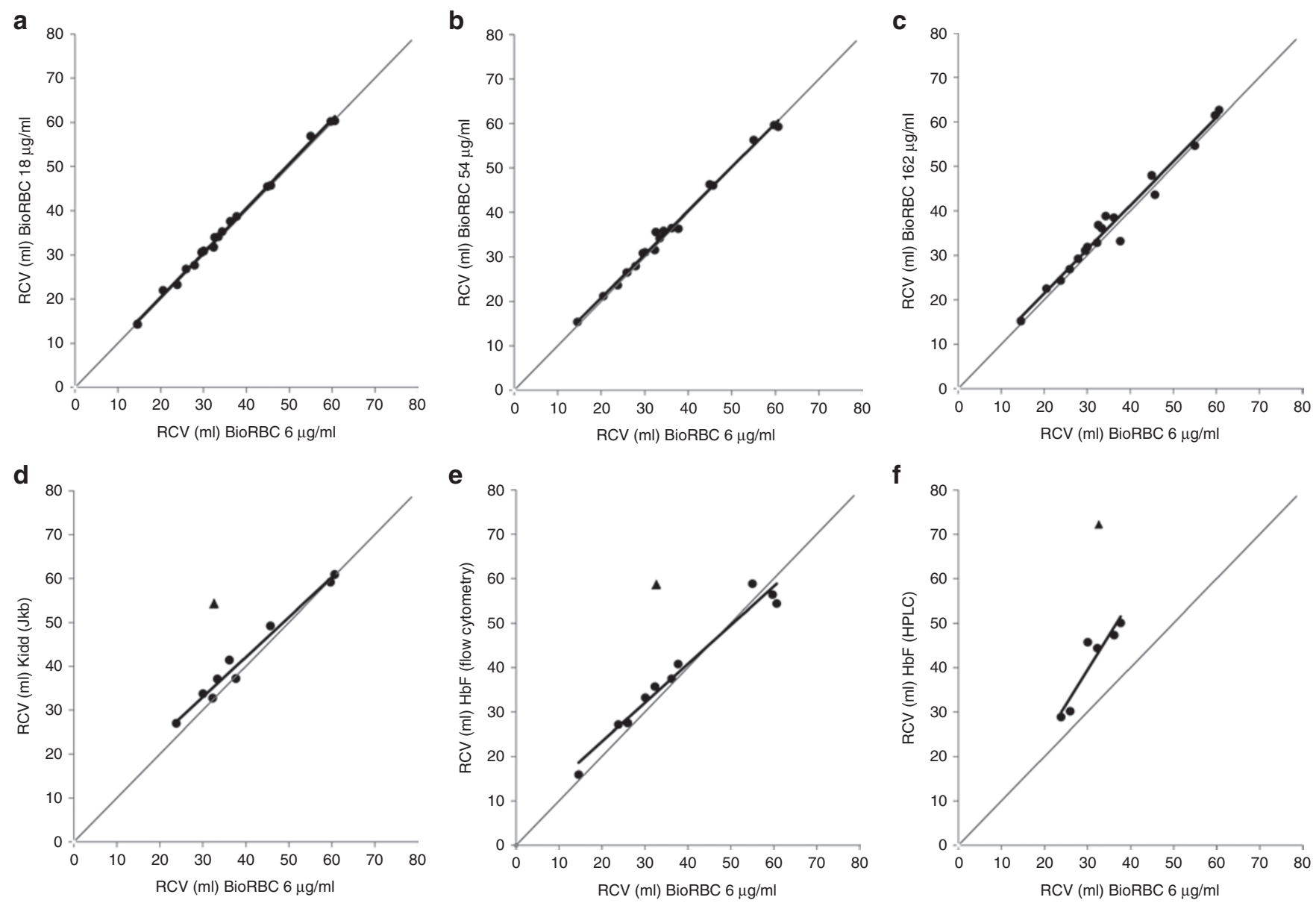

Figure 2. Agreement of red cell volume (RCV) measurements determined at $20 \mathrm{~min}$. Using biotin-labeled red blood cell (BioRBC) densities (a) $18 \mu \mathrm{g} / \mathrm{ml}$, (b) $54 \mu \mathrm{g} / \mathrm{ml}$, and (c) $162 \mu \mathrm{g} / \mathrm{ml}$. (d) Kidd antigen (Jkb). (e) HbF flow cytometry methods plotted vs. RCV measured from the reference BioRBC density. (f) RCVs determined by fetal hemoglobin (HbF) high-performance liquid chromatography (HPLC) method were overestimated compared to the reference BioRBC density. The line of identity is indicated by the thin diagonal gray line. The triangles in panels (e-f) represent the outlier data point.

subjects did not have an appropriate 24-h posttransfusion sample, they were also excluded.

\section{RCV and BV per Kilogram}

Because RCV and BV values at 20-min posttransfusion normalized by body weight are of clinical interest, we calculated the mean pre- and posttransfusion RCV ( $\mathrm{ml} / \mathrm{kg}$ ) and BV $(\mathrm{ml} / \mathrm{kg})$ using each of the four BioRBC densities, Kidd antigen, and both $\mathrm{HbF}$ methods. Mean pretransfusion RCV ranged between 18.9 and $23.6 \mathrm{ml} / \mathrm{kg}$ for the flow cytometric methods, but was $30.8 \mathrm{ml} / \mathrm{kg}$ for HbF HPLC method (Figure 4a). Following RBC transfusion, infant mean $\mathrm{RCV} \mathrm{ml} / \mathrm{kg}$ increased $\sim 50 \%$ for all methods except for RCV determined by $\mathrm{HbF}$ HPLC method where the mean increase was only $37 \%$. Mean posttransfusion $\mathrm{BV}$ ranged between 73.7 and $85.1 \mathrm{ml} / \mathrm{kg}$ when measured using the flow cytometric methods. By contrast, the mean posttransfusion BV measured by the HbF HPLC method was $104.2 \mathrm{ml} / \mathrm{kg}$ (Figure $4 \mathrm{~b}$ ).

\section{DISCUSSION}

This study determined concurrent RCV and $\mathrm{PTR}_{24}$ measured in VLBW infants undergoing clinically indicated allogeneic RBC
Table 2. Parameters and $95 \% \mathrm{Cls}$ of the linear regressions for each method relative to the reference BioRBC density

\begin{tabular}{lccccc}
\hline $\begin{array}{l}\text { Assay } \\
\text { method }\end{array}$ & Slope & $\begin{array}{c}95 \% \mathrm{Cl} \text { of } \\
\text { slope }\end{array}$ & Intercept & $\begin{array}{c}95 \% \mathrm{Cl} \text { of } \\
\text { intercept }\end{array}$ & $R^{2}$ \\
\hline $\begin{array}{l}\text { BioRBC } \\
18 \mu \mathrm{g} / \mathrm{ml}\end{array}$ & 1.01 & 0.98 to 1.04 & 0.3266 & -0.83 to 1.48 & 0.997 \\
$\begin{array}{l}\mathrm{BioRBC} \\
54 \mu \mathrm{g} / \mathrm{ml}\end{array}$ & 0.98 & 0.94 to 1.02 & 1.1777 & -0.45 to 2.81 & 0.993 \\
$\begin{array}{l}\mathrm{B} \text { BioRBC } \\
162 \mu \mathrm{g} / \mathrm{ml}\end{array}$ & 0.99 & 0.90 to 1.08 & 1.6459 & -1.65 to 4.95 & 0.973 \\
$\begin{array}{l}\text { Kidd Jkb } \\
\text { HbF flow }\end{array}$ & 0.91 & 0.78 to 1.04 & 5.6351 & 0.28 to 10.99 & 0.976 \\
$\begin{array}{l}\text { cytometry } \\
\text { HbF HPLC }\end{array}$ & 1.55 & -0.74 to 1.01 & 5.9154 & -0.40 to 11.43 & 0.965 \\
\hline Bb to 2.39 & -7.1417 & -33.44 to 19.17 & 0.869 \\
\hline
\end{tabular}

BioRBC, biotin-labeled RBC; Cl, confidence interval; HbF, fetal hemoglobin; HPLC, highperformance liquid chromatography.

BioRBC densities, $n=18$; Kidd Jkb, $n=9 ;$ HbF flow cytometry, $n=10 ;$ HbF HPLC, $n=6$. Kidd Jka not included because of the small number of available study subjects $(n=5)$.

transfusions using multiple methods of analysis. These methods included flow cytometric analysis of multidensity-labeled BioRBCs, Kidd antigen and $\mathrm{HbF}^{+} \mathrm{RBCs}$, and $\mathrm{HbF}$ protein by HPLC. Our study provides evidence that RCV measured using 
Table 3. Comparison of mean \pm SEM RCV results for different methods at 20 and 90 min

\begin{tabular}{|c|c|c|c|c|}
\hline \multirow{2}{*}{$\begin{array}{l}\text { Assay } \\
\text { method }\end{array}$} & \multicolumn{2}{|c|}{ RCV Mean (SEM) (ml) } & \multirow{2}{*}{$\begin{array}{c}\% \text { Difference }(95 \% \mathrm{Cl}) \\
(90 \mathrm{~min}-20 \mathrm{~min}) \\
\div 20 \mathrm{~min}\end{array}$} & \multirow{2}{*}{$\begin{array}{c}P \\
\text { value }\end{array}$} \\
\hline & $20 \mathrm{~min}$ & $90 \mathrm{~min}$ & & \\
\hline $\begin{array}{l}\text { BioRBC } \\
6 \mu \mathrm{g} / \mathrm{ml}\end{array}$ & $33.7(0.30)$ & $33.4(0.30)$ & $-0.7 \%(-2.8 \%, 1.4 \%)$ & 0.283 \\
\hline $\begin{array}{l}\text { BioRBC } \\
18 \mu \mathrm{g} / \mathrm{ml}\end{array}$ & $34.2(0.30)$ & $34.2(0.30)$ & $-0.2 \%(-2.6 \%, 2.3 \%)$ & 0.821 \\
\hline $\begin{array}{l}\text { BioRBC } \\
54 \mu \mathrm{g} / \mathrm{ml}\end{array}$ & $34.3(0.30)$ & $34.1(0.30)$ & $-0.6 \%(-2.9 \%, 1.8 \%)$ & 0.465 \\
\hline $\begin{array}{l}\text { BioRBC } \\
162 \mu \mathrm{g} / \mathrm{ml}\end{array}$ & $35.0(0.31)$ & $35.1(0.31)$ & $0.5 \%(-3.1 \%, 4.2 \%)$ & 0.683 \\
\hline Kidd Jka & $35.6(0.32)$ & $36.1(0.31)$ & $1.5 \%(-20.0 \%, 28.8 \%)$ & 0.520 \\
\hline Kidd Jkb & $37.9(0.35)$ & $37.7(0.35)$ & $-0.4 \%(-2.8 \%, 2.0 \%)$ & 0.545 \\
\hline $\begin{array}{l}\text { HbF flow } \\
\text { cytometry }\end{array}$ & $37.4(0.37)$ & $36.7(0.36)$ & $-2.0 \%(-9.4 \%, 6.1 \%)$ & 0.388 \\
\hline $\mathrm{HbF} \mathrm{HPLC}$ & $47.6(0.45)$ & $49.7(0.46)$ & $4.5 \%(-6.0 \%, 16.3 \%)$ & 0.120 \\
\hline
\end{tabular}

Table 4. Mean RCV method ratio results relative to $6 \mu \mathrm{g} / \mathrm{ml}$ reference BioRBC density

\begin{tabular}{lcccc}
\hline & \multicolumn{3}{c}{ Average of 20- and 90- min ratios } \\
\cline { 2 - 4 } Assay method & \multicolumn{4}{c}{$95 \% \mathrm{Cl}$} \\
\cline { 2 - 4 } BioRBC $18 \mu \mathrm{g} / \mathrm{ml}$ & 1.018 & 0.995 & 1.042 & 0.14 \\
BioRBC $54 \mu \mathrm{g} / \mathrm{ml}$ & 1.019 & 0.995 & 1.043 & 0.15 \\
BioRBC $162 \mu \mathrm{g} / \mathrm{ml}$ & 1.044 & 1.007 & 1.082 & 0.02 \\
Kidd Jka & 1.067 & 0.995 & 1.145 & 0.07 \\
Kidd Jkb & 1.126 & 0.966 & 1.312 & 0.15 \\
HbF flow cytometry & 1.104 & 0.920 & 1.326 & 0.44 \\
HbF HPLC & 1.449 & 1.103 & 1.903 & $<0.01$ \\
\hline
\end{tabular}

BioRBC, biotin-labeled RBC; Cl, confidence interval; HPLC, high-performance liquid chromatography; RCV, red cell volume.

lowest density reference BioRBC $(6 \mu \mathrm{g} / \mathrm{ml})$ agreed well with RCV measured using BioRBC densities 18 and $54 \mu \mathrm{g} / \mathrm{ml}$, Kidd antigen, and $\mathrm{HbF}$ flow cytometry. $\mathrm{PTR}_{24}$ also agreed well among all methods. All methods required only microliter volumes of blood and none were associated with identifiable safety issues.

Since the 1970s, accurate measurement of RCV in infants has not been reported, primarily for ethical concerns related to unnecessary radiation exposure of infants enrolled in research studies. Simultaneous determinations of multiple distinct RBC populations are not possible with ${ }^{51} \mathrm{Cr}$ or with most other RBC labeling methods. Accordingly, we contend that the multidensity BioRBC method utilizing $<10 \mu$ sample volumes offers substantial potential for advancing our understanding of hematological and cardiorespiratory conditions and disease processes in the smallest, least mature anemic premature infants. Although a large majority of such infants develop significant anemia requiring RBC transfusion, RBC kinetic studies have never before been performed in the smallest, most fragile, high-risk patients being cared for today.
Like the multidensity BioRBC method, the Kidd antigen and both $\mathrm{HbF}$ methods utilize microliter volumes of blood. Although the latter methods can only be performed at the time an allogeneic RBC transfusion is administered, neither requires ex vivo pretransfusion RBC manipulation (i.e., labeling). This feature of the Kidd antigen and HbF methods negates all safety issues other than those inherently associated with clinically ordered RBC transfusions.

In this study, we first demonstrated the agreement among RCV measurements by the methods mentioned above using regression analysis (Figure 2; Table 2). For these comparisons, the lowest BioRBC density was selected as the reference method. This was based on our previous data-supported hypothesis that labeling with the lowest biotin density would perturb RBCs the least $(11,12)$. RCV determined by the four BioRBC densities demonstrated a very close agreement with one another $\left(R^{2}=0.973-0.997\right)$. This observation is similar to our previous RCV results in adults using the same four BioRBC densities (8). Similar agreement was also observed in our adult sheep multidensity BioRBC RCV study with the exception that the highest BioRBC density studied $(96 \mu \mathrm{g} / \mathrm{ml}$ for sheep) slightly overestimated RCV (7.6\%) as compared with the lowest BioRBC density (12 $\mu \mathrm{g} / \mathrm{ml})$ (13). Although in this study, the non-BioRBC RCV determinations also agreed with the reference BioRBC density, the level of agreement tended not to be as strong. When the inexplicable outlier was excluded from the Kidd antigen and $\mathrm{HbF}$ flow cytometry analyses, RCV results of these two methods demonstrated stronger agreement with the reference BioRBC density. The HPLC method of HbF determination demonstrated the weakest correlation with the reference BioRBC density, but HbF HPLC method also had the fewest number of usable data pairs $(n=6)$.

In addition, we demonstrated that 20 min was sufficiently long for complete equilibration of transfused RBCs with the infant's RBCs. RCV determinations can be perturbed by changes in the enrichment of labeled or mismatched RBCs in the immediate (minutes) posttransfusion period as a result of incomplete mixing or equilibration with body distribution pools. As an example of the latter, in sheep, we reported an apparent $37 \%$ increase in RCV during the first 60 min posttransfusion as the circulating transfused RBCs equilibrated with the noncirculating pool of RBCs in sheep (13). In this study, we observed no significant change in RCV determinations for any of the RCV methods between 20- and 90-min posttransfusion (Table 3). These RCV observations are consistent with our previous observations of no change in RCV after $20 \mathrm{~min}$ in adult humans (8). They are also consistent with results reported by Bratteby in term infants in which ${ }^{51} \mathrm{Cr}$-labeled autologous RBCs reached steady-state levels after an initial 10-min mixing phase (14).

We also showed that different BioRBC densities, Kidd antigen mismatch, and $\mathrm{HbF}$ flow cytometric methods can be interchangeably used for determining RCV in infants undergoing $\mathrm{RBC}$ transfusions. Although statistical analyses indicated a significant $(P=0.02)$, but clinically unimportant, $4.4 \%$ overestimate of mean RCV (95\% CI: $0.7-8.2 \%$ ) for the 

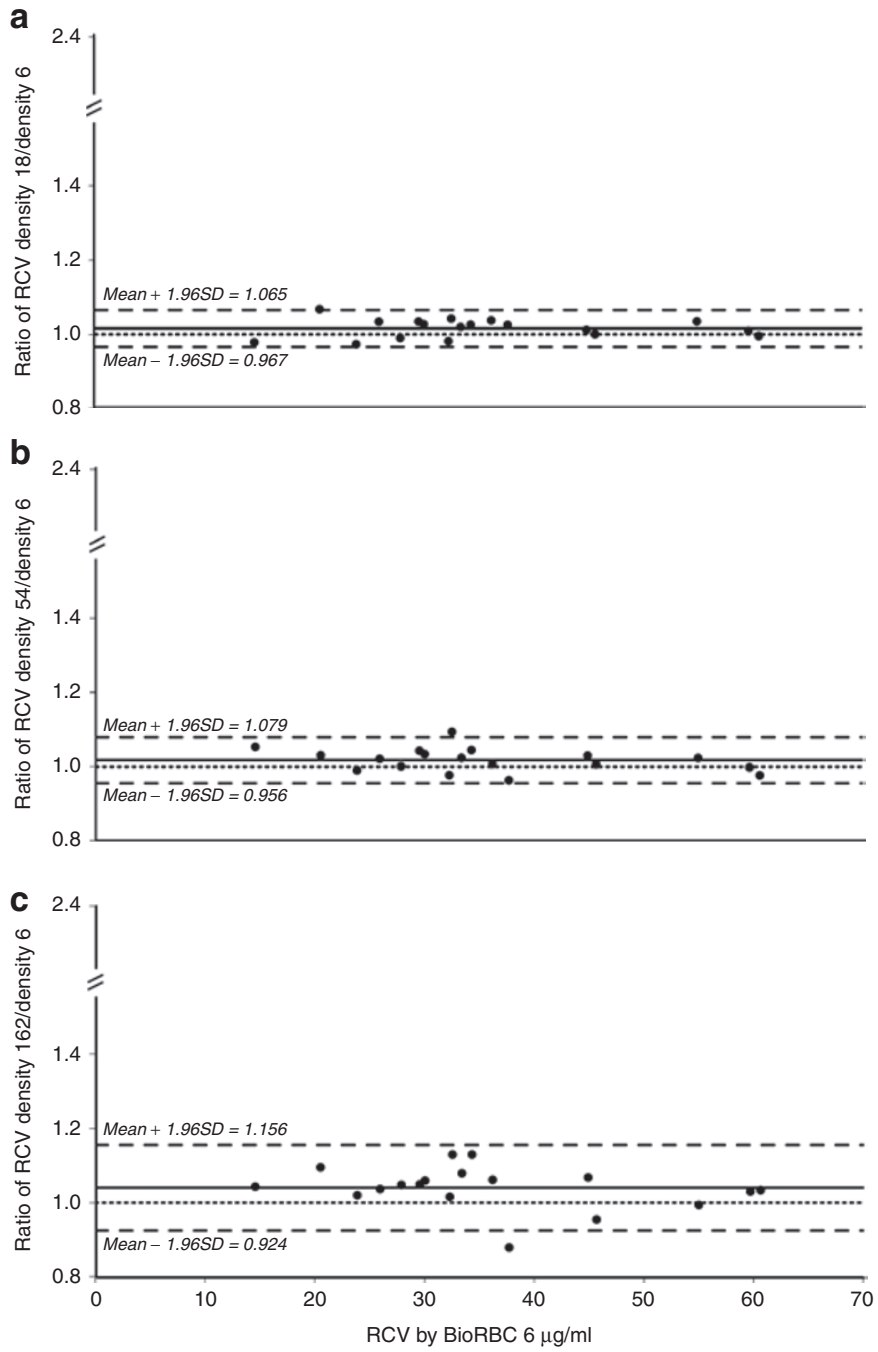
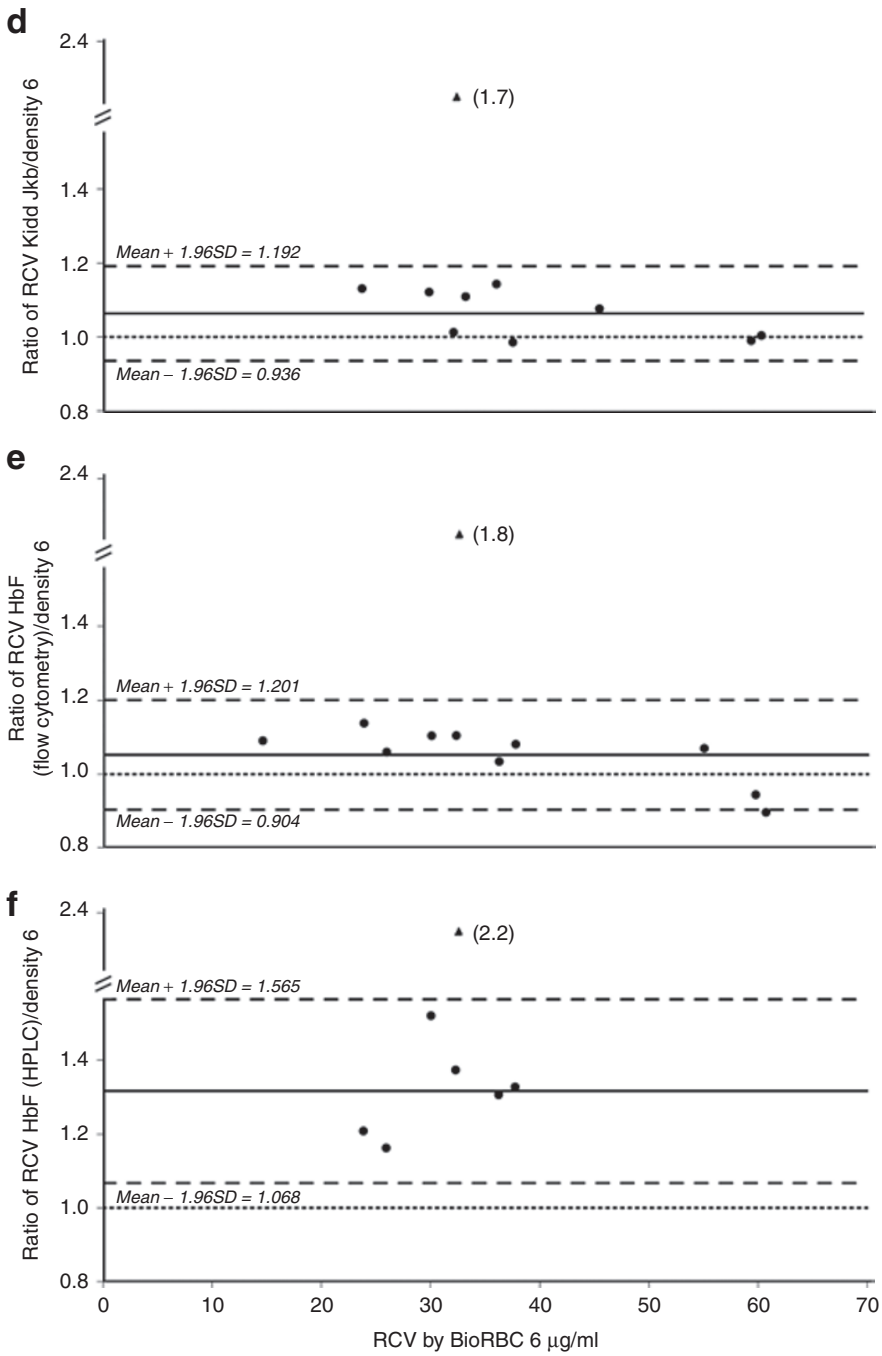

Figure 3. Bland-Altman plots of red cell volume (RCV) relative to the reference biotin-labeled RBC (BioRBC) density compared with (a) BioRBC 18 $\mu \mathrm{g} / \mathrm{ml}$, (b) BioRBC $54 \mu \mathrm{g} / \mathrm{ml}$, (c) BioRBC $162 \mu \mathrm{g} / \mathrm{ml}$, (d) Kidd Jkb, (e) fetal hemoglobin (HbF) flow cytometry, and (f) HbF high-performance liquid chromatography (HPLC). The mean ratio of RCVs (solid line), 95\% confidence interval (dashed line), and ratio $=1.0$ (dotted line) are shown. With the exception of (f) in which HbF HPLC significantly overestimated the limits of agreement for RCV (i.e., the area between the two dashed horizontal lines), all other plots demonstrated good agreement relative to the reference BioRBC density. The triangle data points in panels (d-f) indicate the single outlier data point.

Table 5. Short-term PTR 24 survival of transfused RBCs

\begin{tabular}{lcccc}
\hline Assay method & $\begin{array}{c}\mathrm{PTR}_{24} \text { Mean } \pm \\
\text { SD }(\%)\end{array}$ & $\begin{array}{c}\text { Difference } \\
(95 \% \mathrm{Cl})\end{array}$ & Range of Cl & $P$ value \\
\hline BioRBC $6 \mu \mathrm{g} / \mathrm{ml}$ & $102.5 \pm 3.5$ & $2.50 \%$ & -0.5 to $5.5 \%$ & 0.142 \\
BioRBC $18 \mu \mathrm{g} / \mathrm{ml}$ & $101.0 \pm 3.4$ & $0.90 \%$ & -2.0 to $3.9 \%$ & $>0.99$ \\
BioRBC $54 \mu \mathrm{g} / \mathrm{ml}$ & $101.1 \pm 3.1$ & $1.10 \%$ & -1.5 to $3.8 \%$ & $>0.99$ \\
BioRBC $162 \mu \mathrm{g} / \mathrm{ml}$ & $100.4 \pm 5.1$ & $0.40 \%$ & -4.7 to $5.8 \%$ & $>0.99$ \\
Kidd Jkb & $104.2 \pm 4.5$ & $3.70 \%$ & -2.4 to $10.2 \%$ & 0.377 \\
HbF flow cytometry & $96.4 \pm 4.2$ & $-3.70 \%$ & -9.8 to $2.8 \%$ & 0.424 \\
HbF HPLC & $99.8 \pm 6.9$ & $-0.30 \%$ & -20.6 to $25.2 \%$ & $>0.99$
\end{tabular}

BioRBC, biotin-labeled RBC; Cl, confidence interval; HbF, fetal hemoglobin; HPLC, highperformance liquid chromatography; RCV, red cell volume; $\mathrm{PTR}_{24}$, 24 -h posttransfusion $\mathrm{RBC}$ recovery.

BioRBC densities 6, 18, and $54 \mu \mathrm{g} / \mathrm{ml}, n=14 ;$ BioRBC $162 \mu \mathrm{g} / \mathrm{ml}, n=11$; Kidd Jka, $n=2$; Kidd Jkb, $n=7 ; \mathrm{HbF}$ flow cytometry, $n=7 ; \mathrm{HbF}$ HPLC, $n=4$.
$162 \mu \mathrm{g} / \mathrm{ml}$ BioRBC density (Table 4), we concluded that 162 $\mu \mathrm{g} / \mathrm{ml}$ BioRBC density can be used for RCV determination. By contrast, the HbF HPLC method overestimated RCV by $45 \%$; clinically important discrepancy makes the HPLC method unsuitable for RCV determination.

As hypothesized, based on our previous report in infants (15), PTR $_{24}$ of stored allogeneic RBCs with all methods was not significantly different from $100 \%$, i.e., relative to the 20 -min posttransfusion sample. In addition, $\mathrm{PTR}_{24}$ values of $100 \%$ as determined by methods that do not require ex vivo $\mathrm{RBC}$ modification, i.e., the Kidd antigen and both $\mathrm{HbF}$ methods, supports our hypothesis that biotinylation of RBCs does not cause a change in $\mathrm{PTR}_{24}$ in infants. These findings stand in contrast with stored RBC PTR 24 data in adults in which $\mathrm{PTR}_{24}$ data show a significant decline relative to immediate posttransfusion enrichment (16). 

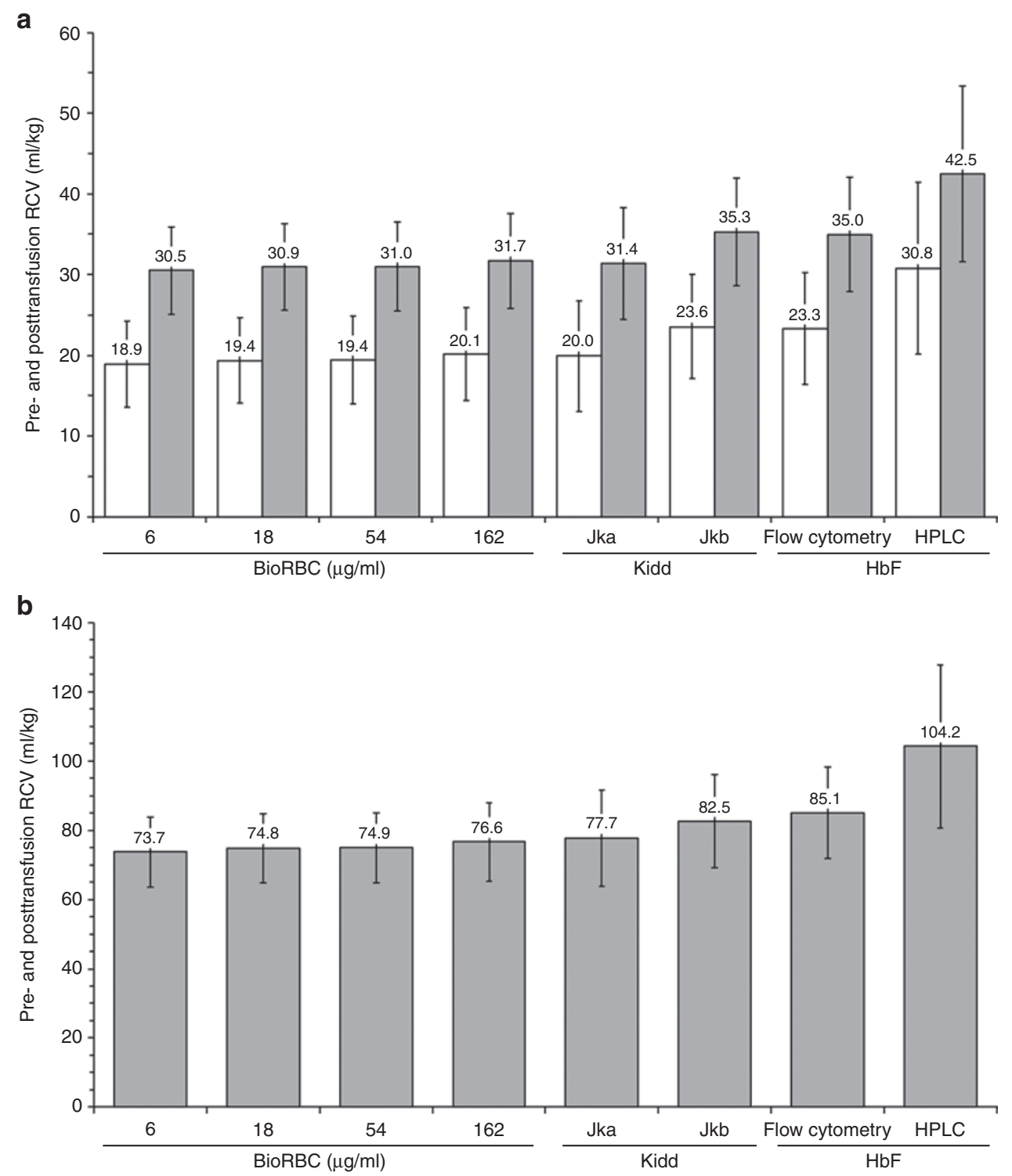

Figure 4. Results of mean $( \pm S D)$ red cell volume (RCV) and blood volume (BV) determinations by each method. (a) Pretransfusion RCV in ml/kg (white bars) and posttransfusion RCV in $\mathrm{ml} / \mathrm{kg}$ (gray bars); (b) posttransfusion. BV in ml/kg. BioRBC, biotin-labeled RBC; HbF, fetal hemoglobin.

Using the RCV data determined in this study, BV per kg was derived by dividing RCV by simultaneously determined HCT measurements. Mean posttransfusion BV derived in this manner ranged from 73.7 to $85.1 \mathrm{ml} / \mathrm{kg}$ for the three flow cytometric methods (Figure 4). Because accurate HCT values immediately before transfusion were not available, it was not possible to determine pretransfusion BV. The close agreement among the posttransfusion BV determined among the flow cytometry methods and the lack of close agreement in the measurement of RCV using HbF protein by HPLC method $(104.2 \mathrm{ml} / \mathrm{kg})$ indicates that the latter method is associated with one or more unidentified systematic errors. While the derived $\mathrm{BV}$ values observed are within the ranges previously reported (17-20), reports of BV are highly variable because some - as in this study - are derived from only RCV and HCT, whereas others are based on direct measurement of both RCV and plasma volume, or plasma volume alone. Studies using the latter approach report larger BVs because of the larger distribution space of the plasma $(18,21)$. In considering infant $\mathrm{BV}$ measurements derived using only RCV and HCT values, it must also be recognized that HCT determinations in infants are not as reproducible as those in older children and adults. This is because of discrepancies in HCT with capillary vs. venous sampling (22).

In conclusion, this study demonstrates that RCV can be safely measured in premature VLBW infants using $<10 \mu \mathrm{l}$ of blood without exposure to radioactivity. Evidence of strong agreement in the concurrent RCV determinations among the flow cytometric methods suggests that these methods provide true and accurate direct measurement of infant RCV. Because of the high sensitivity, safety, and reproducibility of the multidensity BioRBC method and because BioRBC studies can 
be performed using either autologous or allogeneic RBCs (or both simultaneously), we contend that RCV measurement using biotin-labeled RBCs is the most useful and versatile in infants. Kidd antigen and $\mathrm{HbF}$ flow cytometry methods also perform well in the evaluation of the kinetics of allogeneic donor blood and have the advantage of not requiring ex vivo labeling. The application of these newer flow cytometric methods in measuring RCV in the smallest, least mature, and critically ill infants are useful tools in advancing our understanding of their hematological and cardiorespiratory conditions and disease processes.

\section{METHODS}

Institutional Review Boards at the University of Iowa (performance site) and the University of Arkansas for Medical Sciences (analysis site) approved the study. This included approval for administering Kidd mismatched RBCs. Informed written parental consent was obtained.

\section{Study Subjects}

A prospective, convenience sample of 18 newborn infants eligible for study included those being treated with the expectation of survival who were $<31$ wks gestation and expected to receive a clinically indicated RBC transfusion. Infants with congenital anomalies were excluded. Infants who had received previous $\mathrm{RBC}$ transfusions were not excluded. Of the 18 subjects, 8 had received one or more previous allogeneic RBC transfusions.

\section{BioRBC Transfusion}

When a clinical RBC transfusion $(15 \mathrm{ml} / \mathrm{kg}$ packed RBCs with HCT of $\sim 75 \%)$ was ordered, equal aliquots of allogeneic RBC $(1.0 \mathrm{ml} / \mathrm{kg}$ packed RBCs for each density) were labeled at four discrete biotin densities as described below. Each BioRBC population transfused was calculated to produce a final enrichment of $\sim 2 \%$ of the total number of circulating RBCs. Immediately following the infusion of the $11 \mathrm{ml} /$ $\mathrm{kg}$ of the unlabeled clinical transfusion, the remaining $4 \mathrm{ml} / \mathrm{kg}$ containing the four BioRBC densities were infused for a period of $10 \mathrm{~min}$.

\section{Kidd Antigen Mismatch}

Potential donor blood units were screened for identifying Kidd antigen mismatches with infant study subjects when possible. Donor blood units identified as mismatches were then used when a clinical transfusion was ordered. Some infants received mismatched RBCs by chance, i.e., the donor was not prescreened and selected for that infant.

\section{Blood Sampling}

Pre- and post-RBC transfusion blood samples were collected. Posttransfusion infant samples included $150 \mu$ l volumes drawn within 20-90 min following the completion of the BioRBC transfusion. Two of the 18 infants did not have 20 -min posttransfusion samples, so we used 70- and 90-min samples for those two infants as earliest posttransfusion samples. A complete blood count analysis was performed using an automated hematology analyzer (Sysmex XE-2100; Sysmex, Kobe, Japan) for determining RBC count and HCT on the first posttransfusion sample.

Biotinylation of RBCs and Analysis of BioRBCs by Flow Cytometry The method for biotin labeling of RBCs at distinct densities in adult humans was used and aliquots of posttransfusion blood samples were processed for flow cytometric analysis of BioRBCs as described previously (8). Each distinct BioRBC population was detected as a separate peak on the posttransfusion histogram and the number of events counted under each peak was used for determining the enrichment of each BioRBC population.

\section{Analysis of Kidd Antigens by Flow Cytometry}

For $\mathrm{Jka}^{+}$or $\mathrm{Jkb}^{+} \mathrm{RBC}$ flow cytometry analysis, triplicate $3 \mu \mathrm{l}$ aliquots of the pre- and posttransfusion samples were washed to remove plasma proteins following the same procedures as for BioRBCs $(13,23)$. The RBCs were resuspended in $0.3 \mathrm{ml}$ of wash buffer with $2 \%$ bovine serum albumin (A30075; RPI, Mount Prospect, IL) and incubated with $5 \mu \mathrm{l}$ of anti-Jka or anti-Jkb primary antibody (Immucor, Norcross, GA) overnight at room temperature with continuous mixing on a rotating wheel. These RBCs were washed twice and were incubated at $37^{\circ} \mathrm{C}$ for $1 \mathrm{~h}$ with $5 \mu \mathrm{l}$ of Alexa Fluor 488 conjugated secondary antibody (H10120'; Invitrogen, Carlsbad, CA). RBCs were then washed three times and resuspended in wash buffer with $2 \%$ bovine serum albumin (RPI) that had been filtered through a $0.2-\mu \mathrm{m}$ filter to a final volume of $0.5 \mathrm{ml}$. Jka+ $\mathrm{kr} \mathrm{Jkb}^{+} \mathrm{RBCs}$ were enumerated as described above for BioRBCs.

\section{Analysis of $\mathrm{HbF}^{+} \mathrm{RBC}$ by Flow Cytometry}

The method for flow cytometric analysis of $\mathrm{HbF}^{+} \mathrm{RBCs}$ used for detecting $\mathrm{HbF}^{+}$cells following fetomaternal hemorrhage (4) was adapted for determining the RCV in premature infants undergoing adult donor RBC transfusion. The percentage $\mathrm{HbF}^{+} \mathrm{RBC}$ was determined using Invitrogen Fetal Hemoglobin Test (Invitrogen) with fluorescein isothiocyanate-conjugated monoclonal antibody directed against HbF. The manufacturer's manual was followed with the following minor modifications. Duplicate $1.5 \mu \mathrm{l}$ whole-blood samples $\left(\sim 5 \times 10^{6}\right.$ cells $)$ were fixed in $0.25 \mathrm{ml}$ of $0.05 \%$ glutaraldehyde. RBCs were permeabilized in $0.2 \mathrm{ml}$ of $0.1 \%$ Triton X-100. Washed and pelleted RBCs were resuspended in $80 \mu \mathrm{l}$ of phosphate-buffered saline/ bovine serum albumin (Invitrogen/RPI) and incubated with fluorescein isothiocyanate-conjugated $\mathrm{HbF}$ monoclonal antibody for $30 \mathrm{~min}$ at room temperature. RBCs were washed and resuspended in $0.4 \mathrm{ml}$ of $2 \%$ paraformaldehyde before flow cytometry analysis. $\mathrm{HbF}^{+} \mathrm{RBCs}$ were enumerated as described above for BioRBCs.

\section{Analysis of $\mathrm{HbF}$ and $\mathrm{HbA}$ protein by HPLC}

Analysis of $\mathrm{HbA}$ and $\mathrm{HbF}$ proteins by HPLC was performed using the method described by Weitzhandler et al. (24). Briefly, analysis of stored blood samples maintained at $-80{ }^{\circ} \mathrm{C}$ was performed using a Dionex ProPac SCX-10 column (Thermo Scientific, Sunnyvale, CA) interfaced with a Waters 600E pump controller (GenTech Scientific, Arcade, NY), a SPD-10AV UV detector (Shimadzu Scientific Instruments, Columbia, MD), and an auto sampler (Perkin Elmer, San Jose, CA). Replicate hemolysate samples were prepared by mixing $5 \mu \mathrm{l}$ of blood in $1 \mathrm{ml}$ of eluent solution $(50 \mathrm{mmol} / \mathrm{l}$ sodium phosphate and $2 \mathrm{mmol} / \mathrm{l}$ potassium cyanide, $\mathrm{pH}$ 6.0). Ten microliters of sample hemolysate was injected and the relative percentages of $\mathrm{HbF}$ and $\mathrm{HbA}$ proteins derived by using area under the peak analysis using Shimadzu data management software. With this method, acetylated $\mathrm{HbF}$ elutes as a separate peak that is added to the larger nonacetylated $\mathrm{HbF}$ for obtaining the total percentage of $\mathrm{HbF}$ peak protein in the sample.

\section{RCV and BV Calculations}

Posttransfusion RCV was calculated for all methods using the dilution principle as follows:

$$
\begin{aligned}
\mathrm{RCV}(\mathrm{ml})= & \text { Total number of } \mathrm{RBCs}_{\mathrm{Tx}} \\
& \times \frac{\% \mathrm{~A}_{(\text {recipient pre-Tx) }}-\% \mathrm{~A}_{(\mathrm{Tx})}}{\% \mathrm{~A}_{(\text {recipient pre-Tx) }}{ }^{-\% \mathrm{~A}_{(\text {recipient post }-\mathrm{Tx})}}} \times \mathrm{MCV}_{(\text {post-Tx })}
\end{aligned}
$$

where the total number of $\mathrm{RBC}_{(\mathrm{Tx})}=\Sigma$ [volume of individual infusate $\times$ RBC concentration]. The volume of infusate for individual BioRBC densities was determined gravimetrically (11) using a specific gravity for transfused RBCs of $1.05(\mathrm{~g} / \mathrm{ml}) ; \% \mathrm{~A}=$ percentage of individual BioRBC densities $(6,18,54$, or $162 \mu \mathrm{g} / \mathrm{ml}), \mathrm{Jka}^{+}, \mathrm{Jkb}^{+}$, or $\mathrm{HbF}^{+} \mathrm{RBCs}$ (for HPLC, \%HbF protein); Tx = transfusion; pre-Tx = pretransfusion sample; post-Tx = posttransfusion sample; and $\mathrm{MCV}=$ mean corpuscular volume.

Although all study subjects had RCV measurements by BioRBC performed at all four densities, only 14 had Kidd antigen mismatches. For two infants, technical difficulties precluded inclusion of the Kidd antigen results, leaving $12 \mathrm{RCV}$ determinations. For the HbF flow 
cytometry and HbF HPLC determinations, these methods had not been fully developed in our laboratory at the time the study was initiated: only 11 had RCV determined by HbF flow cytometry, and only 7 had RCV determined by HbF HPLC.

The posttransfusion $\mathrm{BV} \mathrm{ml} / \mathrm{kg}$ of each study subject was calculated using the following formula:

$$
\mathrm{BV}(\mathrm{ml} / \mathrm{kg})=\mathrm{RCV}(\mathrm{ml} / \mathrm{kg}) / \text { posttransfusion } \mathrm{HCT}
$$

Because pretransfusion HCT was not measured, pretransfusion RCV was determined by subtracting the total volume of RBCs transfused from posttransfusion RCV.

\section{Statistical Analysis}

Test for differences in mean RCV among the methods was performed by linear mixed model analysis for repeated measures. The natural log transformation of RCV was used for normalizing the data distribution. The mixed model included method, time, and method $\times$ time interactions. In addition to the estimation of the fixed effects in the mixed model, this method of analysis allows for selection of the covariance structure that best fits the variance-covariance of the RCVs for the different methods and times in the same subject. From the linear mixed model analysis, the test for method by time interaction and the test for the posttransfusion time effect were examined. To report mean RCV in the original scale, the method $\ln (\mathrm{RCV})$ means from the fitted linear mixed model were back transformed and the standard error was computed using the delta method. The differences in $\ln (\mathrm{RCV})$ between the BioRBC densities were also back-transformed. This provided estimates for the mean RCV ratio relative to reference BioRBC density.

Bland-Altman plots of the observed RCV ratio for a given density, Kidd antigen (Jkb), or both $\mathrm{HbF}$ methods relative to reference BioRBC method were included to display the distribution of ratios. The plots also show the mean ratio and the $95 \%$ limits of agreement for the mean ratio (i.e., mean $\pm 1.96 \mathrm{SD}$ ).

Descriptive data were expressed as the mean \pm SD. Bonferroni correction for multiple comparisons was used. All the statistical analyses were performed with computer software (SAS, Version 9.3, 2002-2008; SAS Institute, Cary, NC). A $P$ value $<0.05$ was considered significant.

\section{ACKNOWLEDGMENTS}

We thank Robert S. Franco and Peter Veng-Pedersen for their helpful discussions with us regarding technical and theoretical aspects of this study. We appreciate the many contributions of the clinical laboratory staff led by Mitchell J. Owen and overseen by Matthew D. Krasowski, without which this work would not have been possible. We thank the many outstanding clinical research contributions of lowa's neonatal nurse research team (Karen Johnson, Laura Knosp, Nancy Krutzfield, Ruthann Schrock Sara Scott, and Jin Zhou) and the research laboratory team (Earl Gingerich and Jessica Goehring). We thank S. Isil Cevik for her assistance with preparation of figures and Mark Hart for his valuable secretarial assistance. The Sysmex XE-2100 automatic hematology analyzer used in this study was generously provided on an on-loan basis from Sysmex, Kobe, Japan. Finally, we appreciate the willingness of study subject families in allowing their infants to participate.

\section{STATEMENT OF FINANCIAL SUPPORT}

This publication was supported in part by the U.S. National Institutes of Health (NIH) grant P01 HL046925, by the Thrasher Research Fund 0285-3 (Salt Lake City, UT), and by grant UL1RR024979 from the National Center for Research Resources (NCRR). The paper's contents are solely the responsibility of the authors and do not represent the official views of the $\mathrm{NIH}$, the Thrasher Research Fund, or the NCRR.

\section{REFERENCES}

1. Strauss RG. Anaemia of prematurity: pathophysiology and treatment. Blood Rev 2010;24:221-5.

2. Jones JG, Holland BM, Hudson IR, Wardrop CA. Total circulating red cells versus haematocrit as the primary descriptor of oxygen transport by the blood. Br J Haematol 1990;76:288-94.
3. Mock DM, Bell EF, Lankford GL, Widness JA. Hematocrit correlates well with circulating red blood cell volume in very low birth weight infants. Pediatr Res 2001;50:525-31.

4. Davis BH, Olsen S, Bigelow NC, Chen JC. Detection of fetal red cells in fetomaternal hemorrhage using a fetal hemoglobin monoclonal antibody by flow cytometry. Transfusion 1998;38:749-56.

5. Dziegiel MH, Nielsen LK, Berkowicz A. Detecting fetomaternal hemorrhage by flow cytometry. Curr Opin Hematol 2006;13:490-5.

6. Blanchard D, Bruneau V, Bernard D, et al. Flow cytometry analysis of dual red blood cell populations after bone marrow transplantation. Br J Haematol 1995;89:741-7.

7. Hudson IR, Cavill IA, Cooke A, et al. Biotin labeling of red cells in the measurement of red cell volume in preterm infants. Pediatr Res 1990;28:199202.

8. Mock DM, Matthews NI, Zhu S, et al. Red blood cell (RBC) volume can be independently determined in vivo in humans using RBCs labeled at different densities of biotin. Transfusion 2011;51:148-57.

9. Wynn R, Dixon S, al-Ismail SA, et al. Flow cytometric determination of pre-transfusion red cell volume in fetuses and neonates requiring transfusion based on $\mathrm{RhD}+$ dilution by transfused $\mathrm{D}$ - red cells. $\mathrm{Br} \mathrm{J}$ Haematol 1995;89:620-2.

10. Arndt PA, Kumpel BM. Blood doping in athletes-detection of allogeneic blood transfusions by flow cytofluorometry. Am J Hematol 2008;83: 657-67.

11. Mock DM, Matthews NI, Zhu S, et al. Red blood cell (RBC) survival determined in humans using RBCs labeled at multiple biotin densities. Transfusion 2011;51:1047-57.

12. Mock DM, Matthews NI, Zhu S, et al. Comparison of red blood cell survival in sheep determined using red blood cells labeled with either biotin at multiple densities or $[14 \mathrm{C}]$ cyanate: validation of a model to study human physiology and disease. Transfusion 2012;52:963-73.

13. Mock DM, Matthews NI, Zhu S, et al. Red blood cell (RBC) volume can be independently determined in vivo in the sheep using ovine RBCs labeled at different densities of biotin. Transfusion 2010;50:2553-64.

14. Bratteby LE. Studies on erythro-kinetics in infancy. 8. Mixing, disappearance rates and distribution volume of labelled erythrocytes and plasma proteins in early infancy. Acta Soc Med Ups 1967;72:249-71.

15. Strauss RG, Mock DM, Widness JA, Johnson K, Cress G, Schmidt RL. Posttransfusion 24-hour recovery and subsequent survival of allogeneic red blood cells in the bloodstream of newborn infants. Transfusion 2004;44:871-6.

16. Hess JR, Hill HR, Oliver CK, et al. Twelve-week RBC storage. Transfusion 2003;43:867-72.

17. Aladangady N, Aitchison TC, Beckett C, Holland BM, Kyle BM, Wardrop CA. Is it possible to predict the blood volume of a sick preterm infant? Arch Dis Child Fetal Neonatal Ed 2004;89:F344-7.

18. Bratteby LE. Studies on erythro-kinetics in infancy. XI. The change in circulating red cell volume during the first five months of life. Acta Paediatr Scand 1968;57:215-24.

19. Phillips HM, Holland BM, Abdel-Moiz A, et al. Determination of red-cell mass in assessment and management of anaemia in babies needing blood transfusion. Lancet 1986;1:882-4.

20. Riley AA, Arakawa Y, Worley S, Duncan BW, Fukamachi K. Circulating blood volumes: a review of measurement techniques and a meta-analysis in children. ASAIO J 2010;56:260-4.

21. Mollison PL, Veall N, Cutbush M. Red cell and plasma volume in newborn infants. Arch Dis Child 1950;25:242-53.

22. Rivera LM, Rudolph N. Postnatal persistence of capillary-venous differences in hematocrit and hemoglobin values in low-birth-weight and term infants. Pediatrics 1982;70:956-7.

23. Mock DM, Matthews NI, Strauss RG, Burmeister LF, Schmidt R, Widness JA. Red blood cell volume can be independently determined in vitro using sheep and human red blood cells labeled at different densities of biotin. Transfusion 2009;49:1178-85.

24. Weitzhandler M, Farnan D, Horvath J, et al. Protein variant separations by cation-exchange chromatography on tentacle-type polymeric stationary phases. J Chromatogr A 1998;828:365-72. 